\title{
Gujjar Community Rehabilitation from Rajaji National Park: Moving Towards an Integrated Approach for Asian Elephant (Elephas maximus) Conservation
}

\author{
Ritesh Joshi ${ }^{1}$ and Rambir Singh ${ }^{2}$ \\ 1. G. B. Pant Institute of Himalayan Environment and Development, Garhwal Unit, \\ Srinagar-Garhwal, 246 174, Uttarakhand, India \\ E-mail: ritesh_joshi2325@yahoo.com \\ 2. SERC Division, Department of Science and Technology (DST), Government of India, \\ Technology Bhavan, New Mehrauli Road, New Delhi, 110 016, India \\ E-mail: rambir@yahoo.com
}

KEYWORDS Asian Elephant. Conservation. Gujjar Rehabilitation. Rajaji National Park. Wildlife

\begin{abstract}
Rehabilitation of Gujjar community from the Rajaji National Park area is a persistent and better effort in the direction of wildlife conservation in India. On one hand it has provided the better opportunity for livelihood to pastoral Gujjars and on the other hand it has promoted the regeneration of forest wealth along with movement related activities of wildlife. The major objectives of the study are to generate the database of impact of Gujjar rehabilitation on frequent movement of wildlife. Eight forest ranges were surveyed for about seven years before and after the resettlement of Gujjar and all the data on animal sighting, movement and vegetation component were recorded. Currently wild animals are utilizing whole of the forest area frequently for their routine activities whereas before the resettlement of Gujjars wild animals generally used the water points after sunset. The undisturbed conditions created as a result of the resettling of the pastoral Gujjars, have had a noticeable effect on the elephant and tiger population of the forest area. As per the records of 1998 a total of 1390 families were existing in the park area and after the commencement of the programme 512 families were resettled at Pathri area and 613 were relocated at Gaindikhatta area. Presently 265 families are to be relocated who are residing inside the national park area. After the establishment of state Uttarakhand the rehabilitation programme has conducted very rapidly and over the past six years five forest ranges of the park are freed from the Gujjars.
\end{abstract}

\section{INTRODUCTION}

The Shivalik foothills are one of the world's most spectacular landscapes, encompassing the tall grasslands and the Shorea robusta (Sal) forests. This entire belt is natural home of Asian elephants (Elephas maximus) besides many other wild animals like tiger, leopard, spotted deer and sloth bear. Therefore, Ministry of Environment and Forests, Government of India has declared this area as an Elephant Reserve (Rajaji National Park) with sole aim of maintaining the viable population of Asian elephants in their natural habitat. Infact, the Shivalik landscape is one of the last few places in the world where

Postal Address of Corresponding Author:

Dr. Ritesh Joshi, G. B. Pant Institute of Himalayan Environment and Development

Garhwal Unit, Srinagar-Garhwal, 246 174,

Uttarakhand, India

Phone: + $911346252603(\mathrm{O})$,

$+919456601923$

E-mail: ritesh_joshi2325@yahoo.com elephants exist and offers urgent need for conservation. This conservation area in India's lesser Himalayan region falls under sub tropical moist deciduous forest type with extensive stands of Shorea robusta (Sal), Mallotus phillipinensis (Rohini), Acacia catechu (Khair), Adina cordifolia (Haldu), Terminalia bellirica (Bahera), Ficus bengalensis (Bar) and Dalbergia sissoo (Shisham) in its premise besides many other important fodder plant species. From conservation point of view it appears to be India's one of the most successful national park and its development has helped to boost the population of Asian elephants in their natural habitat.

Rehabilitation of Gujjar community from the Rajaji National Park (RNP) area is a persistent and better effort in the direction of wildlife conservation in India (Fig. 1). On one hand it has provided the better opportunity for livelihood to pastoral Gujjars and on the other hand it has promoted the regeneration of forest wealth along with movement related activities of wildlife. Conservation of biological diversity was often 


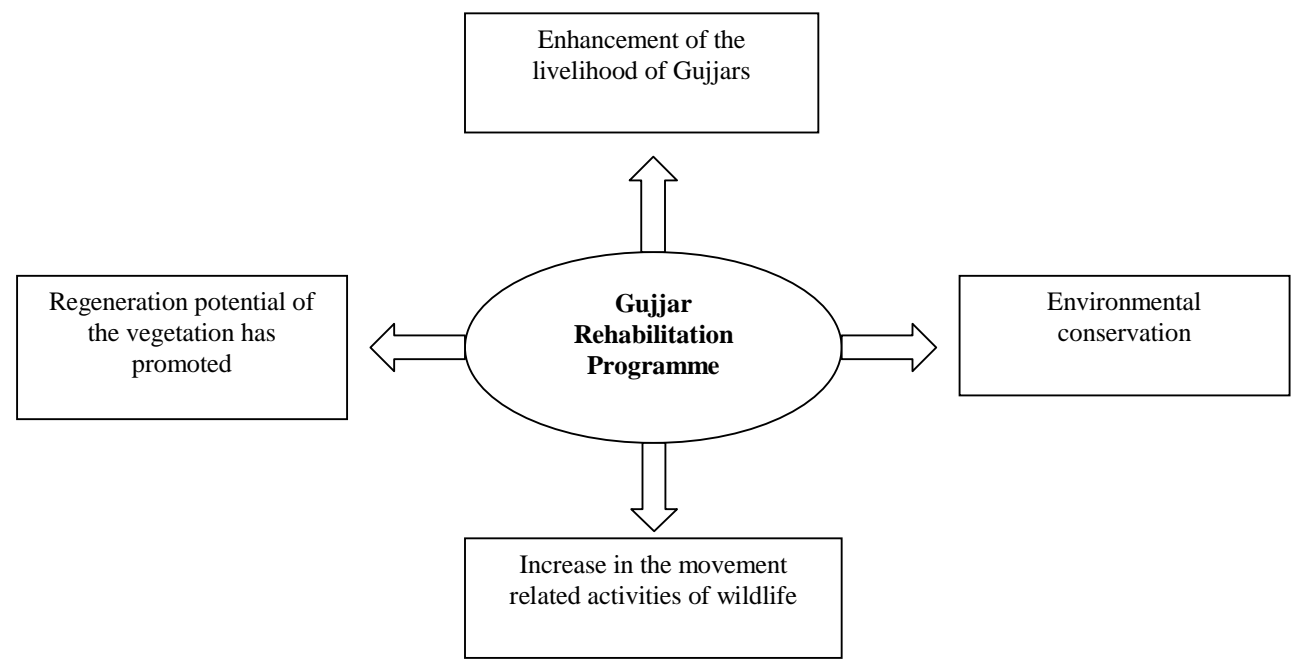

Fig. 1. Impact of the Gujjar rehabilitation programme.

associated with relocation of resident peoples and village relocation has clearly emerged as an important issue in conservation that needs to be examined for more closely than it has been in the past (Rangarajan and Shahabuddin 2006). The undisturbed conditions created as a result of the resettling of the pastoral Gujjars, have had a noticeable effect on the elephant and tiger population of the forest area. Spread over an area of $820 \mathrm{Km}^{2} \mathrm{RNP}$ is the second largest protected area of state Uttarakhand. This area is the northwestern end of the area of distribution of the elephant, tiger and the king cobra. This study gives emphasis to Gujjar rehabilitation programme in the Rajaji National Park area and frequent movement of wild animal along with the flagship species elephant. All of these findings may have wider implications for developing predictive models of human - elephant interactions. The present note is a part of our long-term study on the behavioural biology of Asian elephants in and around the RNP area.

\section{METHODS}

\section{Study Area}

RNP is spread over an area of $820 \mathrm{~km}^{2}$ in and around the Shivalik foothills (Fig. 2), which lies in between the lesser Himalayas and the upper Gangetic plains, which are a major natural habitat for Asian elephants and also the terminal point of the north-western elephant population range. The protected area lies between $29^{\circ} 52^{\prime}$ to $30^{\circ} 16^{\prime} \mathrm{N}$ and $77^{0} 52^{\prime}$ to $78^{\circ} 22^{\prime} \mathrm{E}$. Spread across Haridwar, Dehradun and Pauri districts of Uttarakhand state, RNP has been designated as a reserved area for the "Project Elephant" by the Ministry of Environment and Forests, Government of India with the sole aim of maintaining the viable population of Asian elephants in their natural habitat. The river Ganges has cut across these hills at Haridwar. The study is ongoing in the eight forest ranges (Haridwar, Chilla, Motichur, Kansrao, Chillawali, Dholkhand, Ramgarh and Gohri) of the RNP. The altitude lies between $302-1000 \mathrm{~m}$ asl. The study site falls in sub-tropical moist deciduous forest type. The study area is largely covered with moist deciduous forest type with the sub types of moist Shivalik Sal (Shorea robusta) and the remaining area is mostly under mixed forest vegetation type. The study area is enriched with a few annual and perennial water streams in its premise.

\section{Data Collection}

For studying the impact of Gujjar rehabilitation programme, eight forest ranges of the RNP were in-depthly surveyed for about seven years. For observing the impact of Gujjar rehabilitation programme, all the study sites were investigated thoroughly (2000) and interactions were made with most of the Gujjar families to observe their 


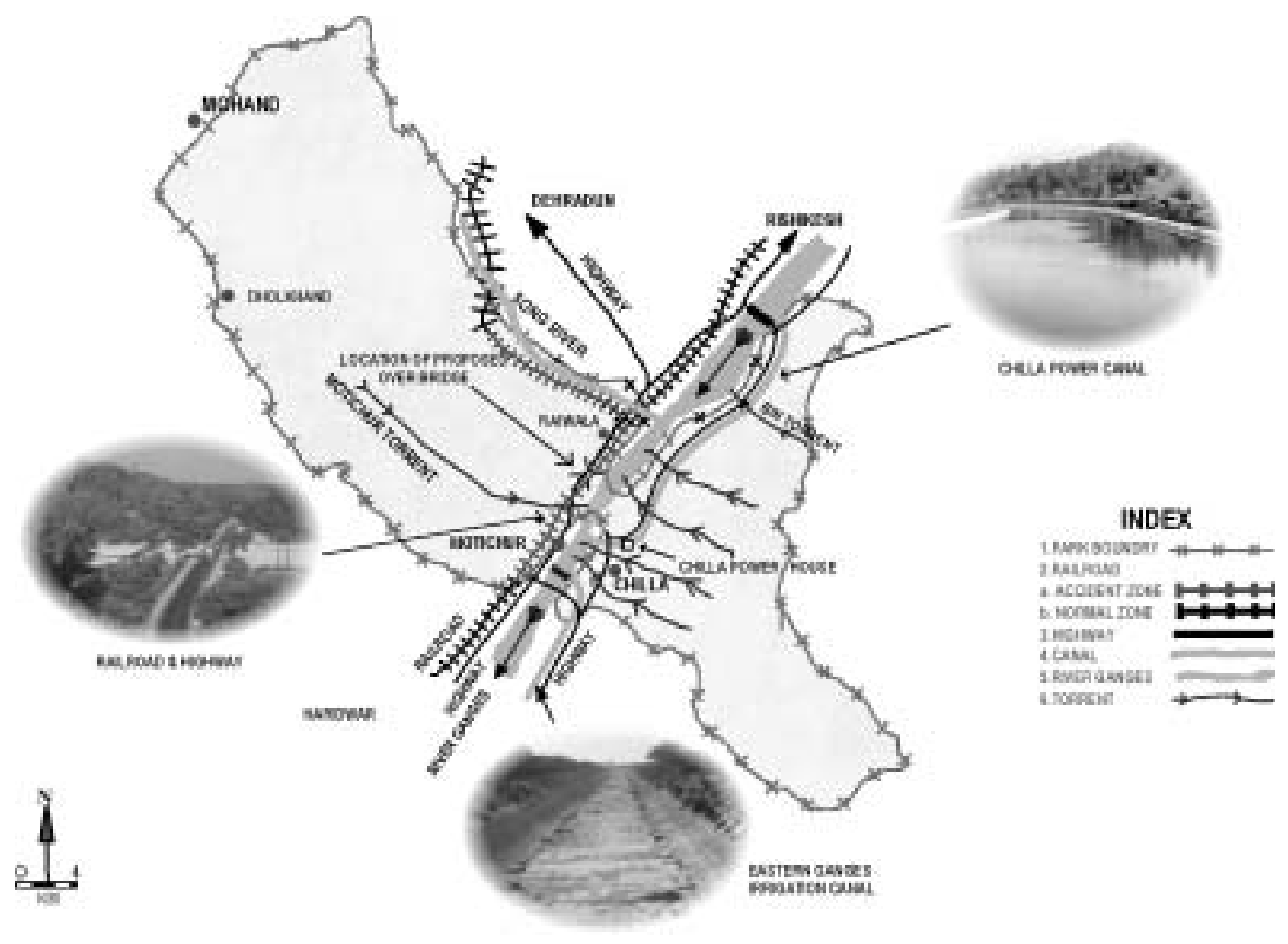

Fig. 2. Map of the study area.

livelihood status. Again after the relocation of Gujjar families all the areas, where abandoned deras (shelters) of Gujjars were present inside the forest area were investigated thoroughly (2006) for observing the impact of rehabilitation programme on the regeneration potential of vegetation and movement related activities of wild animals. Besides, survey was also conducted at both of the rehabilitation sites for assessing their livelihood status. The previous status of the forest (before the resettlement of Gujjars) and current status (after the relocation of Gujjars), was thoroughly examined from both angles i.e. environmental conservation and socio-economic upliftment of rural communities' point of view. The sharp natural behaviours of wild animals along with the major species - elephants were observed both during day and in night period with precautions. For studying the ecological responses, including the movement, feeding and mating behaviour of elephants, different areas were visited frequently. The observations started at early hours in the morning, as it is the best time to assess the movement of wild animals in open areas and four hours in the afternoon i.e. before the sunset. Field binocular was also used for observing their various behaviours without disturbing the animal from an adequate safe distance. The data collected is the part of the animal monitoring activities. The mentioned research work in this manuscript has complied with the current laws of the country. The research work is presently ongoing with the financial assistance of Department of Science and Technology, Government of India and with the prior permission of state Government. The research works only comprises of field oriented studies but does not include any experimental work with animals.

\section{RESULTS AND DISCUSSION}

\section{History}

The Gujjars came to the Shivaliks from Jammu 
nearly 200 years ago as part of the dowry of a princess of Nahan in present-day Himachal Pradesh. Here they raised buffalo and practiced transhuman pastoralism, spending autumn (approximately October to April) in the Shivaliks and the summer and the rainy season (May to September) in the alpine pastures of Himalayas. Migration between these grazing zones took up to the three months and their population increased rapidly throughout their new habitation. In 2000, nearly 6,000 Gujjars with about 13,000 livestock lived in deras (shelters) along the water courses in the park. In addition to the Gujjar owned livestock, 3,000 odd head of cattle grazed in the park. Over the years, over grazing by the livestock and lopping of fodder trees has allowed the under growth of many weeds. One of the major problem we have observed was that they always constructed their deras near to the natural water holes and the dung deposited by the livestock pollutes these water sources and water becomes impure for elephants.

Gujjars are the nomadic community whose members stay inside the forest in huts, which are locally known as deras. Their major occupation is rearing cattle like buffalo and cow and selling milk in the local market. On an average one Gujjar family has 15-20 buffalos and the relatively better families may own 30-40 buffalo each. On account of their routine requirements particularly fodder need, Gujjars have been inflicting heavy pressure on precious forest resources of the park. Their cattle had competed against the wild animals for meeting their requirement of water and grazing. During the recent past tree lopping by Gujjars not only retards the natural regeneration of various species but also exposes the ground floor leading to infestation by various weeds. A total of 512 families were present in the RNP area in 1985 , whereas just after a decade their number rises rapidly and as per the available data in 1998 number of families was enhanced to 1390 (Table 1).

In view of the provisions of Wildlife (Protection) Act, 1972 the first attempt to resettle the Gujjars from the park area was made in year 1984, by the Uttar Pradesh government but government does not receives complete success due to some drawbacks in the project. This scheme was formulated for 512 families of Gujjars living regularly in the reserve forest areas, which were notified in 1983 as RNP. Based on the official records, 512 families of Gujjars living in the RNP area were identified for relocation at Pathri
Table 1: Scenario of Gujjar families inside the Rajaji National Park during 1985 and 1998.

\begin{tabular}{llrr}
\hline S. No. & Forest range & \multicolumn{2}{c}{ No. of families } \\
\cline { 3 - 4 } & & 1985 & 1998 \\
\hline 1. & Haridwar & 85 & 254 \\
2. & Chilla & 181 & 193 \\
3. & Motichur & 37 & 116 \\
4. & Kansrao & 11 & 85 \\
5. & Chillawali & 65 & 260 \\
6. & Dholkhand & 116 & 234 \\
7. & Ramgarh & 17 & 99 \\
8. Gohri & - & 149 \\
Total families that were to & 512 & 1390 \\
be rehabilitated & & \\
\hline
\end{tabular}

rehabilitation site in Haridwar district. These families were identified for relocation on an 80 hectare patch of reserve forest of Pathri region in Haridwar forest division. Meanwhile, after the establishment of state Uttarakhand the rehabilitation programme has conducted very rapidly and over the past six years five forest ranges of the park were freed from the Gujjars. They are relocated to two rehabilitation sites namely Gaindikhatta and Pathri. Keeping in view the welfare of Gujjar's community Uttarakhand government has providing them all the necessary facilities like water, medicare, roads, agriculture land, primary school, solar fencing, mid day scheme (Angan bari Yojna), widow pension for physically challenged, regular visit of veterinary doctor, clean toilets, establishment of fear price shop and issuing of ration card.

In one hand movement related activities of wild animal has got increased and in other hand Gujjars are continuously doing appropriate efforts for the betterment of their life style. Each family was given a little over two acres ( 0.8 hectare) of arable land, in which currently they are cultivating many vegetable along with cereal crops. Each family was also provided a house site and Rs. 2000 to shift its belongings to new area. Besides, they are also permitted to collect the timber from nearby forests to build their deras. As per our talks with the Gujjars they are fully satisfied with this government decision and they are assuming that through this approach they can improve their livelihood. As per the data of 1998 a total of 1390 families were existing in the park area and after the commencement of the programme 512 families were resettled to the Pathri area and 613 were relocated to the Gaindikhatta area (Table 2). Presently 265 families are to be relocated who are residing inside the national park area. 
Table 2: Current scenario of Gujjar rehabilitation programme in the Rajaji National Park.

\begin{tabular}{|c|c|c|c|c|c|c|c|}
\hline \multirow[t]{2}{*}{$\begin{array}{l}\text { S. } \\
\text { No. }\end{array}$} & \multirow[t]{2}{*}{$\begin{array}{l}\text { Name of the } \\
\text { forest range }\end{array}$} & \multicolumn{2}{|c|}{$\begin{array}{c}\text { Number of } \\
\text { families }\end{array}$} & \multirow[t]{2}{*}{$\begin{array}{c}\text { Relocated in } \\
\text { Pathri }\end{array}$} & \multirow[t]{2}{*}{$\begin{array}{l}\text { Relocated in } \\
\text { Gaindikhatta }\end{array}$} & \multirow[t]{2}{*}{$\begin{array}{l}\text { Relocated } \\
\text { in all }\end{array}$} & \multirow[t]{2}{*}{$\begin{array}{l}\text { Balance to } \\
\text { be relocated }\end{array}$} \\
\hline & & 1985 & 1998 & & & & \\
\hline 1. & Haridwar & 85 & 254 & 194 & 60 & 254 & - \\
\hline 2 . & Chilla & 181 & 193 & - & 193 & 193 & - \\
\hline 3. & Motichur & 37 & 116 & 101 & 15 & 116 & - \\
\hline 4. & Kansrao & 11 & 85 & 43 & 42 & 85 & - \\
\hline 5. & Chillawali & 65 & 260 & 2 & 83 & 85 & 175 \\
\hline 6. & Dholkhand & 116 & 234 & 130 & 102 & 232 & 02 \\
\hline 7. & Ramgarh & 17 & 99 & 42 & 51 & 93 & 06 \\
\hline 8. & Gohri & - & 149 & - & 67 & 67 & 82 \\
\hline & Total & 512 & 1390 & 512 & 613 & 1125 & 265 \\
\hline
\end{tabular}

\section{Legal Problems}

The Gujjar relocation programme at since very beginning was adversely affected due to lagal cases. Mr. Mohemmad Safi, the so called Chairman of Gujjar Welfare Society filed a petition in Hon'ble Supreme Court of India. Hon'ble Supreme Court of India in its order dated 07.12.1990 in WP No. 79/ 89 Mohemmad Safi Vrs State of Uttar Pradesh clearly indicated that the scheme should be implemented as expeditiously as possible. As per the above order dated 07.12.1990 learned counsel of the petitioner Gujjars had assured the Hon'ble Supreme Court that they will move from the RNP area within four months to rehabilitation site. The other facilities as per rehabilitation scheme will be made available to Gujjars only after their shifting from the RNP area.

In 1993 Rural Litigation and Entitlement Kendra (RLEK), an NGO claiming to work for the welfare of Gujjars filed a petition in National Human Rights Commission (NHRC) opposing rehabilitation on the grounds of allegation of harassment. In 1999 the NHRC issued orders for appointment of a Retired Judge of High Court to verify the willingness of Gujjar families to move outside the park. Later on the High Court requested the Commission to appoint an acting District Judge for the purpose. This was accepted and District Judge, Haridwar was appointed to verify willingness of Gujjar families to shift out of the park area. In 2001 District Judge, Haridwar was transferred and new District Judge joined. The new District Judge refused to verify the willingness of Gujjar families to shift as the former District Judge was appointed by name. In 2002 Hon'ble High Court, Nainital was requested to nominate District Judge, Haridwar ex-officio. The Hon'ble High Court, Nainital has appointed District Judge, Haridwar by post for the purpose.

\section{Impact of Gujjar Rehabilitation Programme on Wildlife}

Gujjar deras were mostly situated near to the water sources inside the forest area. Besides, they are responsible for lopping of many important fodder plant species like Ficus bengalensis, Ficus religiosa, Ficus rumphii, Emblica officinalis, Bridelia retusa, Anogeissus latifolia, Aegle marmelos, Dendrocalamus strictus, Bauhinia variegata, Grewia oppositifolia, Lagerstroemia parviflora, Oogeinia oogenensis, Garuga pinnata, Schleichera oleosa, and Lannea coromendelica. All of these reasons have restricted the wildlife to some extent to move frequently within their home range. One important point, which was observed during the study period is that animals are currently utilizing all of the internal corridors, which passes through the abandoned deras of Gujjars. Besides, wild animals are currently utilizing all of the available waterholes to fulfill their routine requirements through out the day. Regeneration potential of forest has got strengthen just after the relocation of Gujjars as lopping and grazing by their cattle's was completely stopped after this programme.

Lopping of trees in forest areas is a conventional practice and a significant forest-based economic activity for villagers residing in the vicinity of forest areas since it produces intermittent benefits to them from forest crops in the form of firewood and fodder (Gupta 2002). It has been experienced that the villagers understand and recognize the need for future consumption but due to high rate of time preference for out turn obtained from lopping and lack of technical knowledge about it, intensity of lopping becomes heavy and quite often the entire crowns of trees are lopped excepting a few young branches. This adversely affects the growth of trees, which 
constitute resource base of lopping itself and thus the productivity of the forest area as a whole (Rawat 1993).

As per the observations of our earlier surveys (before the resettlement of Gujjars) it was observed that the Gujjars children used to make loud noise during day time while playing nearer to their deras. Besides, they also kept their surroundings cleared from trees or shrubs for better visibility of wild animals. Sometimes it was also reported that if elephant came nearer to their deras they used to burn the fire woods and screamed to deter the animal. Gujjars generally used all of the rough routes present inside the park for their entire day activities and few routes among them are the internal corridors for elephants to cross the forest beats in which elephant's had faced difficulties to pass on during the day hours. Their presence throughout the day brought in outsider on foot, by bicycle and motorcycle (where rough route is available) for various transactions, leading to enormous disturbance in the wildlife habitat throughout the year. A noticeable effect on the forest was seen just after the relocation programme. The major changes primarily comprises of enhancement of wilderness in those places, which were used by Gujjar as their deras. It was inferred from the results of the study that their abandoned deras are presently replaced by huge variety of vegetation like Saccharum spontaneum, Saccharum munja, Holarrhena antidysenterica, Trewia nudiflora, Murraya spp., Cynodon dactylon and Syzygium cumini. Besides, the water holes are presently completely recharged with natural water and are being used by wildlife.

Another important impact on movement of wild animals that was seen is that in many places animal left the tendency of straying into the cultivated area. Elephants traditionally often leave the forest to feed in nearby villages, usually at night period. Even before 1998 elephants were reported to be raiding yields but their outside movement was more common in few areas from 2001 (Joshi et al. 2001). This may also be due to rapid expansion of industries and human settlements around the protected area. The Kharkhari, Bilkeshwar, Tibri and Ravli forest beats of the park area were attached by villages, so the impact of increasing pressure on account of a variety of anthropogenic activities on the movement pattern of the elephants of these sites was much more (Joshi and Verma 2000). As during last decades the general economic condition of people has bettered in this area, this has leaded to increase in the purchase power, social interactions, tourists and religious activities of the people at all levels (Joshi and Joshi 2006).

In the adjoining areas of Hardwar - Bijnor National highway various stakeholders has constructed shopping complexes, check posts and shrines and all of these spots are working as a barriers as far elephant's movement is concerned (Joshi and Singh 2008). Presently park authority is also doing an effort to eradicate the Lantana camara (Lantana) inside the park area as a result of which many of the species like Syzygium cumini (Jamun), Holarrhena antidysenterica (Kura), Saccharum spontaneum (Kans) and Cynodon dactylon (Doob Grass) are growing rapidly.

The situation is just opposite in adjoining area of Haridwar forest division (which is not in the park area), Gujjars are still existing within the protected area and are currently utilizing all of the waterholes and fodder resources frequently for their routine requirements as the result of which few forest patches are rapidly replaced by toxicious weed like Parthenium histerophorous (Gajar grass) and Lantana camara (Lantana / Kuri jhari). Elephants must scarify the ground in order to feed on the short grasses due to domestic buffaloes being grazed. In this type of situations elephants are diverting themselves to the peripheral forests or they are performing their outside movements towards the agriculture fields, which generally lead to crop depredation by elephants. This has created man-elephant conflict in this part of globe.

Resettlement of the tribal people from protected areas is a controversial subject. India has debated the relationship between local communities and protected areas since the 1800s. In 1878 Frederic Le Play challenged state monopoly over forest management and argued against re-location of local communities. Nevertheless, these issues remain unresolved and India continues to relocate unwilling villagers out of protected areas. According to project planners, humans threaten the biodiversity in these protected areas through harvesting timber and non-timber forest produce, hunting, uncontrolled fires, conversion to agricultural lands, industrial and commercial development, high human population density and growth, high incidence of poverty and large number of livestock. People 
living in the core areas of these reserves will need to be relocated (Weeks and Mehta 2004).

During the course of our study on the behavioural biology of Asian elephant, we have encountered frequently the elephants to observe their natural behaviours during the day hours. Besides, we have also recorded the better elephant's movement along with mating behaviour among elephants, which will strengthen their inter breeding especially during their long-term migration. An important point, which we have observed during the study period, is that male bull elephants show the phenomenon of 'musth' during most of the months of the year, which is the sigh of their healthiness. Associational behaviour among bull elephants was reported to increase after 2004 whereas during 2000-2001 bull association was observed very rare.

However, this extreme move has been resorted in order to save some of the endangered wild animal species such as elephant and tiger. This extreme move has been resorted to in order to save some of the precious wildlife species such as tiger, the elephant and the sambar. Ecological and behavioural studies have shown that these species thrive only when there are no disturbances in the core areas of the habitats (Johnsingh 2005). Study inferred that wild animals are presently utilizing all of the waterholes and due to this animal sighting is quite frequent in various forest ranges. Ecological and behavioural studies have shown that wildlife survives only when there are no disturbances in the buffer and core areas of the natural habitats especially nearer to the water points. When the Gujjars were present, the elephants and other wild animals usually emerged out of the forests only in late evening hours but presently they are performing their frequent traditional movement in all the forest ranges. In addition, ancient elephant corridors are still in use by these Pachyderms. These corridors has provided connectivity to various protected areas such as Hardwar forest division, Dehradun forest division and Lansdowne forest division.

Gujjar rehabilitation programme has strengthen the regeneration potential of forest vegetation especially fodder plant species. Out of total seven plant species, which are reported to growing rapidly in those abandoned areas where once Gujjar deras were present, five are categorized under fodder species for elephant. In few of the areas elephants used to rest under cool shade of Ficus bengalensis trees, which are present near to abandoned deras. The presence of Gujjar in RNP has created problems to the elephants. They lop the trees badly and in a very unscientific way, which affects the growth and the regeneration of the trees in the forest (Singh and Sharma 2001). One of the important aspect of the programme is to remove the livestock population of Gujjar but the major objectives are not fulfilled at present. Because few of the Gujjar families, which were resettled to rehabilitation sites has shifted their cattle's to their cousin relatives those are still living inside the forest area. As per the results of this study it was recommended strongly that Shyampur and Chriapur forest ranges of the Hardwar forest division should be merged in the RNP area, so that we can provide the better habitat to flagship species - elephants along with other wild animals and for fulfilling our major objectives.

India has globally significant biodiversity values that are currently threatened by deforestation, land degradation and unregulated exploitation of natural resources. The program is central to conserving elephant's and its habitat while adopting community participatory approach. Additionally, support rural communities through providing sound scientific, livelihood and development opportunities. Gujjar rehabilitation programme in the RNP area will definitely ensure the long-term wildlife survival in this part of globe and fulfill the issue of conservation of biological diversity. The long-term survival of the Asian elephant of this region would depend on the socio-economic as well as ecological consideration.

\section{ACKNOWLEDGEMENTS}

We are thankful to the Science and Engineering Research Council (SERC), Department of Science and Technology (DST), Government of India for providing financial support and thanks are due to Dr. R. C. Srivastava, Scientist 'G' \& Advisor and Dr. Jagdish Chander, Scientist 'F', DST, for their cooperation and valuable suggestions. Dr. U. Dhar, Director, G. B. Pant Institute of Himalayan Environment and Development, Kosi - Katarmal, Almora and Dr. R. K. Maikhuri, Scientist Incharge of the Garhwal Unit of G. B. Pant Institute of Himalayan Environment and Development are acknowledged for providing facilities, encouragement and suggestions. Prof. B. D. Joshi, Department of 
Environmental Sciences, Gurukul Kangri University, Hardwar and Dr. S. P. Sinha, Coordinator- Swamp Deer Project, C/o Wildlife Institute of India are highly acknowledged for their comments during the field investigations. Shri Srikant Chandola, Additional Principal Chief Conservator of Forests (Wildlife), Government of Uttarakhand and Shri G. S. Pande, Director of the Rajaji National Park are acknowledged for giving the permission to carry out the research work in the said area. Thanks are to various concerned forest officials and staff for providing help during the field investigation.

\section{REFERENCES}

Gupta SK 2002. Aspects and Sustainability of Joint Forest Management. Dehradun: Bishen Singh Mahendra Pal Singh.

Johnsingh AJT 2005. Conservation: lessons from Uttaranchal. Frontline 22(14): 2-15.

Joshi R, Verma JK 2000. Impact of human activities on the movement pattern of elephants (Elephas maximus) in Hardwar range of the Rajaji National Park area. Nature and Biosphere, 5(1 \& 2): 35-37.
Joshi R, Joshi H, Verma JK 2001. Crop depredation around Hardwar range by elephants (Elephas maximus) in the Rajaji National Park, India. Nature and Biosphere, 6(1\&2): 45-49.

Joshi R, Joshi BD 2006. Impact of anthropogenic activities on elephant (Elephas maximus) around few religious places: A case study from the Rajaji National Park, Uttaranchal, India. Him J Env Zool, 20(1): 87-90.

Joshi R, Singh R 2008. Asian elephant (Elephas maximus) and riparian wildlife corridors: A case study from lesser-Himalayan zone of Uttarakhand. The Journal of American Science, 4(1): 63-75.

Rangaran M, Shahabuddin G 2006. Displacement and relocation from protected areas: towards a biological and historical synthesis. Conservation and Society, 4(3): 359-378.

Rawat JK 1993. Economic considerations in tree lopping. Indian Forester, 119: 703-707.

Singh AP, Sharma RC 2001. Conflicts between linear developments and Asian elephants in sub-Himalayan zone of Uttaranchal. In: CL Irwin, P Garrett and KP McDermott (Eds.): Ecology and transportation. Raleigh, NC: Centre for Transportation and the Environment, North Carolina State University, pp. 423-432.

Weeks P, Mehta S 2004. Managing people and landscapes: IUCN's protected area categories. J Hum Ecol, 16 (4): 253-263. 